\title{
Agricultural
}

\section{and Resource}

\section{Economics Review}
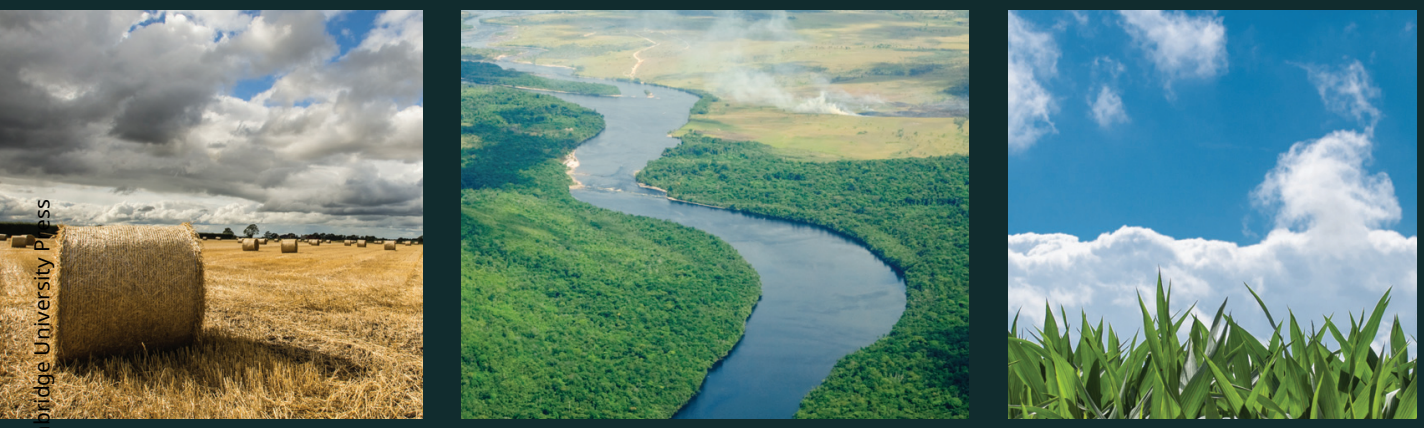

The official publication of the Northeastern Agricultural and Resource Economics Association (NAREA) 


\section{AGRICULTURAL AND \\ RESOURCE ECONOMICS \\ REVIEW}

Volume 47 / Number 1 . April 2018

\section{Selected Papers}

Does Advertising Content Matter? Impacts of Healthy Eating and Anti-Obesity Advertising on Willingness to Pay by Consumer Body Mass Index - Ruitong Wang, Jura Liaukonyte, and Harry M. Kaiser..

Enhancing Adoption Studies: The Case of Residential Stormwater Management Practices in the Midwest - Dong Won Shin and Laura McCann

Climate Change, Salinization and High-Yield Rice Production in Coastal Bangladesh - Susmita Dasgupta, Md. Moqbul Hossain, Mainul Huq, and David Wheeler.

Modeling the Choice of Tillage Used for Dryland Corn, Wheat and Soybean Production by Farmers in Kansas - Elizabeth Canales, Jason S. Bergtold, and Jeffery R. Williams. 90

The Competition of Beverage Products in Current Market: A Composite Demand Analysis " Yan Heng, Lisa A. House, and Hyeyoung Kim.

The Hurdles to Greater Adoption of Anaerobic Digesters - Cortney Cowley and B. Wade Brorsen

Effects of Tariff Concessions on Japanese Beef Imports by Product and Source - Andrew Muhammad, Amanda M. Countryman, and Kari E. R. Heerman.

Bayesian Downscaling Methods for Aggregated Count Data - Clayton

P. Michaud and Thomas W. Sproul 


\title{
AGRICULTURAL AND \\ RESOURCE ECONOMICS REVIEW
}

\author{
Volume 47 / Number 1 • April 2018
}

MANAGing Editor

Dave Abler

Pennsylvania State University

EDITORS

Jill Caviglia-Harris

Salisbury University

Hung-Hao Chang

National Taiwan University -

Taiwan

\section{Editorial BoARd}

Amy Ando
University of Illinois - United States
Toshi Arimura
Waseda University - Japan
Junfei Bai
China Agricultural University - China

Marc Bellemare

University of Minnesota - United States

Derek Brewin

University of Manitoba - Canada

Jeremy Clark

University of Canterbury - New Zealand

Cornelis Gardebroek

Wageningen University - Netherlands

Stephen Goetz

Penn State University - United States

Shreekant Gupta

Delhi School of Economics - India

John Hoddinott

Cornell University - United States

Yanhong Jin

Rutgers University - United States

Harry Kaiser

Cornell University - United States

Shunsuke Managi

Kyushu University - Japan

Matin Qaim

University of Göttingen - Germany

Kimberly Rollins

University of Nevada, Reno - United States

James Shortle

Penn State University - United States

Diogo Souza Montiero

Newcastle University - United Kingdom

Jordan Suter

Colorado State University - United States

Patrick Walsh

Landcare Research - New Zealand

Xiaohua Yu

University of Göttingen - Germany
Historian

John Halstead

University of New Hampshire - United States

WeBMASTER

Sahan T. M. Dissanayake

Colby College - United States

\section{Association Officers}

PRESIDENT William Wheeler U.S. Environmental Protection Agency

PRESIDENT-ELECT Sarah Jacobson Williams College

PAST PRESIDENT Martin D. Heintzelman Clarkson University

SECRETARY-TREASURER John Halstead University of New Hampshire

\section{Executive Committee}

Charles Abdalla

Pennsylvania State University

Director 2015-2018

Elena Besedin

ABT Associates

Industry Representative

Allison Borchers

U.S. Forest Service

Government Representative

Sarah Cline

U.S. Department of the Interior

Director 2016-2019

Gal Hochman

Rutgers University

Director 2016-2019

Donna Ramirez Harrington

University of Vermont

Director 2014-2017

Mario Teisl

University of Maine

Director 2014-2017

Emi Uchida

University of Rhode Island

Director 2015-2018 